В. Т. Санжаровский. - Москва: Издательство «Химия», 1970. $-370 \mathrm{c}$.

2. Седов, Л. И. Механика сложной среды. Т. 1 [Текст]/

Л. И. Седов. - Москва: Издательство, 1970. - 492 с.

3. Работнов, Ю. Н. Ползучести элементов конструкций

[Текст] / Ю. Н. Работнов. - Москва: «Наука», 1966. - 780 с.

4. Москвитин, В. В. Сопротивление вязко-упругих материалов [Текст] / В. В. Москвитин. - Москва: Издательство «Химия», 1972. - 370 с.

5. Амензаде, Ю. А. Теория упругости [Текст] / Ю. А. Амензаде. - Москва: Издательство «Высшая школа», 1976. -287 c.

6. Бугаков, И. И. Ползучесть полимерных материалов [Текст] / И. И. Бугаков. - Москва: Издательство "Наука", 1973. - 287 с.

Рекомендовано до публікації д-р техн. наук, професор Гасанов Р. А. Дата надходження рукопису 23.01.2015

Хейрабади Газаля Сабир кызы, асистент, кафедра “Прикладная механика", Азербайджанская Государственная Нефтяная Академия, ул. Кадырли, 75, г. Баку, Азейрбаджан, AZ106

E-mail:qezale@mail.ru

УДК 656.211

DOI: $10.15587 / 2313-8416.2015 .36936$

\title{
МЕТОД ВИЗНАЧЕННЯ УБЕЗПЕЧЕНОЇ ЗОНИ ВИКОНАННЯ РОБІТ НА КОЛІЯХ ЗАЛІЗНИЧНИХ СТАНЦІЙ
}

\author{
(C) С. О. Змій, В. П. Мороз
}

Розроблений метод визначення убезпеченої зони виконання робіт на коліях станції, який засновано на геометричному представленні колійного розвитку, має на меті обтрунтувати необхідність виконання оповіщення та убезпечення прачівників при переміщенні рухомого складу по суміжній з зоною виконання робіт колії. Отримані результати рекомендовано для використання у системах автоматичного оповіщення прачівників залізничного транспорту

Ключові слова: колійний розвиток, геометрична модель колійного розвитку, убезпечена зона виконання робіт, габарит зони виконання робіт, габарит наближення будівель

The developed method for determining of safe work areas on the tracks station, which is based on geometric representation of trackage, aims to justify the need to carry insurance and alert staff when moving rolling stock on the area adjacent to the track works. The results are recommended for use in automatic alerts of railway transport workers

Keywords: Track development, geometric model of trackage, protected area of work, size of work area, structure clearance gauge

\section{1. Вступ}

Для убезпечення працівників, що виконують роботи на коліях залізничних станцій, необхідно своєчасно виявити небезпеку, яку створює при переміщенні рухомий склад та своєчасно їх про це оповістити. На даний час, в основному, на станції задачу оповіщення виконує черговий по станції

При проведенні дослідження відповідних дій чергових по станції та алгоритмів функціонування існуючих систем автоматичного оповіщення встановлено, що при переміщенні рухомого складу по суміжній 3 зоною виконання робіт колії не існує науково обгрунтованих вимог необхідності оповіщення та убезпечення цих працівників. Таким чином, роботи на коліях станції можуть бути, як необгрунтовано припинені без відсутності небезпеки з боку рухомого складу, так і не убезпеченні за відсутності необхідного оповіщення.

\section{2. Постановка проблеми}

На теперішній час відсутній науково обгрунтований метод, що дозволяє однозначно визначити необхідність виконання оповіщення працівників на коліях станції при переміщенні рухомого складу по суміжній $з$ зоною робіт колії.

Для рішення поставленої проблеми необхідно вирішити наступні задачі:

- визначення убезпеченої зони виконання робіт на коліях;

- визначення умов убезпеченого виконання робіт при переміщенні рухомого складу по суміжній колії з зоною робіт.

\section{3. Літературний огляд}

Проблемам убезпечення виконання робіт на коліях залізничних станцій присвячено значну кількість робіт. У діючих правилах технічної експлуатації [1] та стандарті [2] регламентовано лише загальні умови необхідності оповіщення. У 
роботах [3, 4] надано порядок дій чергового по станції при наявності працівників на коліях, але відсутня інформація щодо обгрунтування умов необхідності їх оповіщення.

\section{4. Визначення убезпеч- ченої зони виконання робіт на коліях станції \\ При встановленні марш-} руту через зону виконання робіт черговий по станції (ДСП) відповідно до вимог [1, 3] зобов'язаний оповістити працівників на колії про встановлення такого маршруту. Якщо ж зона виконання робіт знаходиться на елементі колійного розвитку сусіднього 3 маршрутом на небезпечній відстані [4, 5], то ДСП також зобов'язаний оповістити працюючих.

В основу реалізації функції оповіщення в системах автоматичного оповіщення покладено аналіз стану елементів однониткового плану станції (рис. 1) [6, 7]. ДСП виконує функції оповіщення аналізуючи інформацію про переміщення рухомого складу також на основі однониткового плану станції, відображеного на табло.

У зв'язку 3 неоднозначністю встановлення необхідності оповіщення та убезпечення працюючих на коліях пропонується перейти до геометричного визначення габариту елементів колійного розвитку (рис. 2), що також дозволить підвищити ефективність функціонування систем автоматиного оповіщення.

Для визначення елементів колійного розвитку, які знаходяться на небезпечній відстані один від одного необхідно визначити кординати перетину габариту наближення будівель [8] та убезпеченої зони виконання робіт - габариту зони виконання робіт (ГЗВР).

У відповідності до [4, 5, 8] убезпеченою зоною виконання робіт можна прийняти відстань 4 м від крайньої рейки або 4,76 м від вісі колії (рис. 3). Таким чином необхідно габарит наближення будівель, який встановлено [8], доповнити габаритом зони виконання робіт (рис. 4).

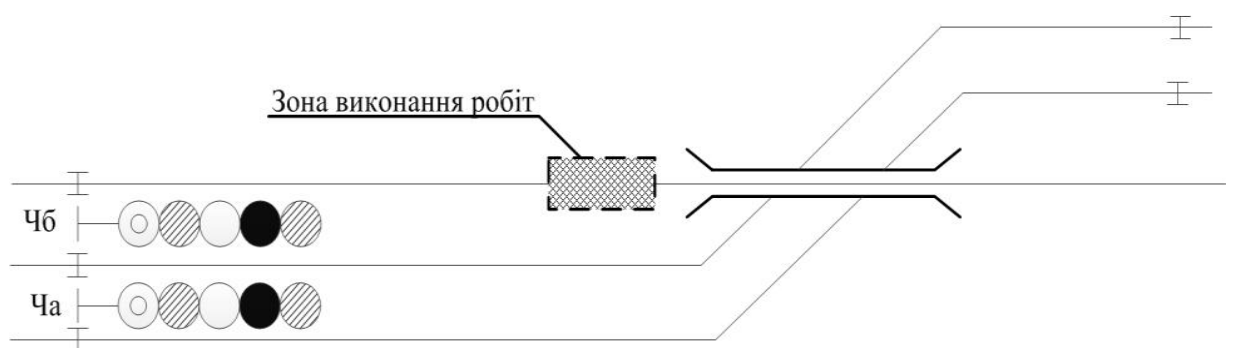

Рис. 1. Однонитковий план станції

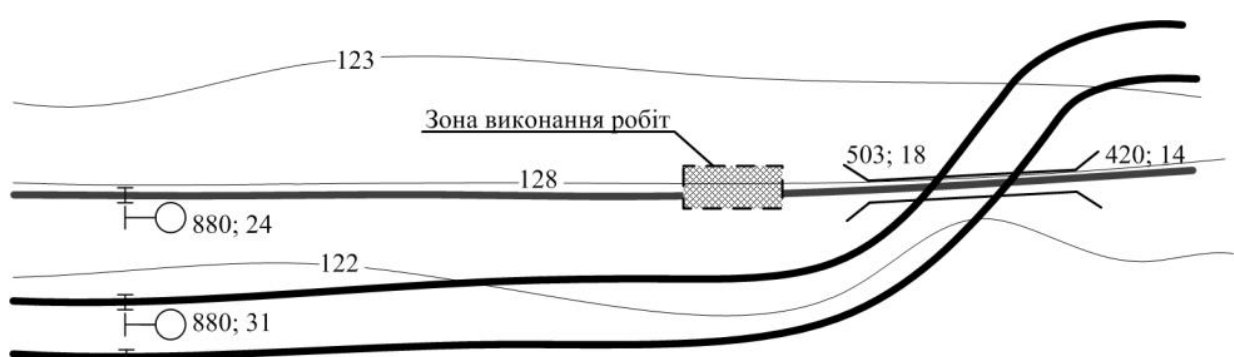

Рис. 2. План станції масштабі

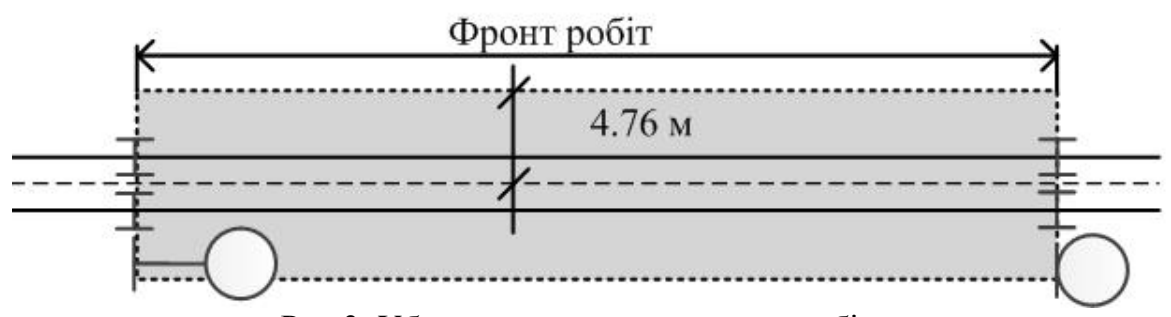

Рис.3. Убезпечена зона виконання робіт

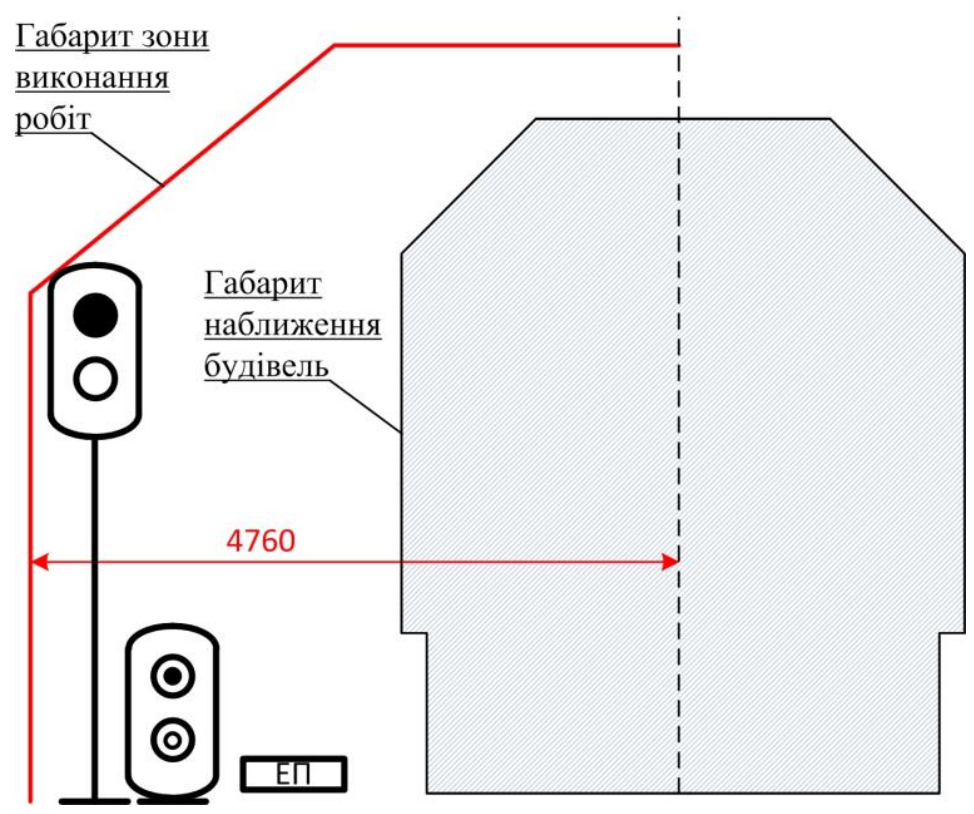

Рис. 4. Габарит рухомого складу, який доповнено габаритом зони виконання робіт 
Роботи на станції можуть виконуватися на прямій ділянці колії, кривій 3 радіусом R або на точковому об'єкті - ізолюючому стику, світлофорі, тощо.

У зв'язку з вищеозначеним необхідно встановити:

- чи належить елемент колійного розвитку а $\epsilon$ А габариту зони виконання робіт $\phi$, тобто а $\epsilon \phi$ (рис. 5);

- чи перетинається хоча би одна зі сторін ГЗВР $з$ елементом колійного розвитку (АВ), тобто $(A B) \cap \phi \neq \varnothing$.

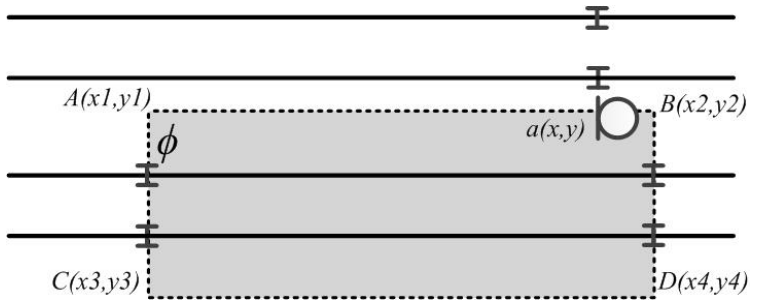

Рис. 5. Визначення приналежності координати об'єкту ГЗВР

Так як координати елементів на станції визначаються відносно поста електричної централізації [10], то

$$
a \in \phi:\left\{\begin{array}{c}
\left(x_{\max } \pm x_{1}\right) \leq\left(x_{\max } \pm x\right) \leq\left(x_{\max } \pm x_{4}\right) \\
y_{1} \leq y \leq y_{4}
\end{array},\right.
$$

де $x_{\max }$ - координата найвіддаленішого об’єкту у парній горловині.

Знак додавання використовується для об'єктів, що знаходяться у непарній горловині, віднімання - у парній.

Знаходження перетину в координаті $G(x, y)$ ділянки колії $(E F)$ з координатами $E(x 5, y 5)$ і $F(x 6, y 6)$ із ГЗВР $\phi$ з координатами $A(x 1, y 1)$ і $B(x 2, y 2)$ (Рис.6) використано рівняння прямих $[0,0]$ :

$$
\begin{aligned}
& \frac{x-\left(x_{\max } \pm x_{1}\right)}{\left(x_{\max } \pm x_{2}\right)-\left(x_{\max } \pm x_{1}\right)}=\frac{y-y_{1}}{y_{2}-y_{1}} \\
& \frac{x-\left(x_{\max } \pm x_{5}\right)}{\left(x_{\max } \pm x_{6}\right)-\left(x_{\max } \pm x_{5}\right)}=\frac{y-y_{5}}{y_{6}-y_{5}} .
\end{aligned}
$$

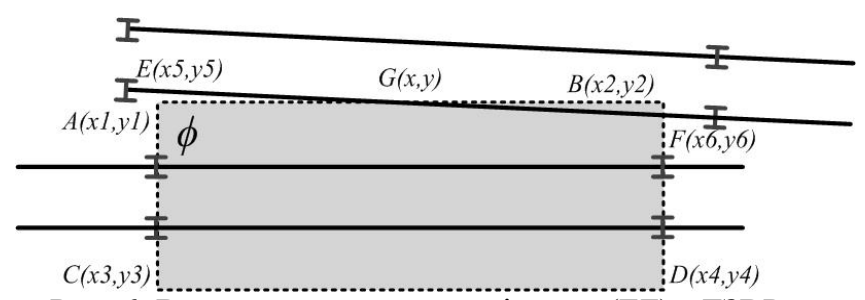

Рис. 6. Визначення перетину ділянки (EF) з ГЗВР

3 рівнянь (2) та (3) можливо визначити координати перетину $x$ та $y[11,12]$ :

$$
\begin{gathered}
\mathrm{x}=\frac{\left(\left(x_{\max } \pm x_{1}\right) \cdot y_{2}-\left(x_{\max } \pm x_{2}\right) \cdot y_{1}\right) \cdot\left(\left(x_{\max } \pm x_{6}\right)-\left(x_{\max } \pm x_{5}\right)\right)-\left(\left(x_{\max } \pm x_{5}\right) \cdot y_{6}-\left(x_{\max } \pm x_{6}\right) \cdot y_{5}\right) \cdot\left(\left(x_{\max } \pm x_{2}\right)-\left(x_{\max } \pm x_{1}\right)\right)}{\left(y_{1}-y_{2}\right) \cdot\left(\left(x_{\max } \pm x_{6}\right)-\left(x_{\max } \pm x_{5}\right)\right)-\left(y_{5}-y_{6}\right) \cdot\left(\left(x_{\max } \pm x_{2}\right)-\left(x_{\max } \pm x_{1}\right)\right)}, \\
\mathrm{y}:=\frac{\left(y_{5}-y_{6}\right) \cdot \mathrm{x}-\left(\left(x_{\max } \pm x_{5}\right) \cdot y_{6}-\left(x_{\max } \pm x_{6}\right) \cdot y_{5}\right)}{\left(x_{\max } \pm x_{6}\right)-\left(x_{\max } \pm x_{5}\right)}
\end{gathered}
$$

Для того, щоб перетин належав даним відрізкам, треба його обмежити, тобто перевірити умову:

$$
(E F) \cap \phi \neq \varnothing:\left\{\begin{array}{c}
\left(x_{\max } \pm x_{1}\right) \leq x \wedge\left(x_{\max } \pm x_{2}\right) \geq x \wedge\left(x_{\max } \pm x_{5}\right) \leq x \wedge\left(x_{\max } \pm x_{6}\right) \geq x \\
y_{1} \leq y \wedge y_{2} \geq y \wedge y_{5} \leq y \wedge y_{6} \geq y
\end{array} .\right.
$$

У тому випадку, коли колійні ділянки $\epsilon$ кривими 3 радіусом $R$ визначення перетину виконується наступним чином.

Припустимо, що одна колійна ділянка $\epsilon$ радіусом $R$ (рис.7). Спочатку необхідно перенести центр кола в початок координат, виправивши відповідну константу $C$ у рівнянні прямої. Таким чином, отримано коло 3 центром в $(0,0)$ радіусу $R$ i прямою (наприклад, ГЗВР), друга - кривою $3 \quad$ пряму з рівнянням $A x+B y+C=0$.

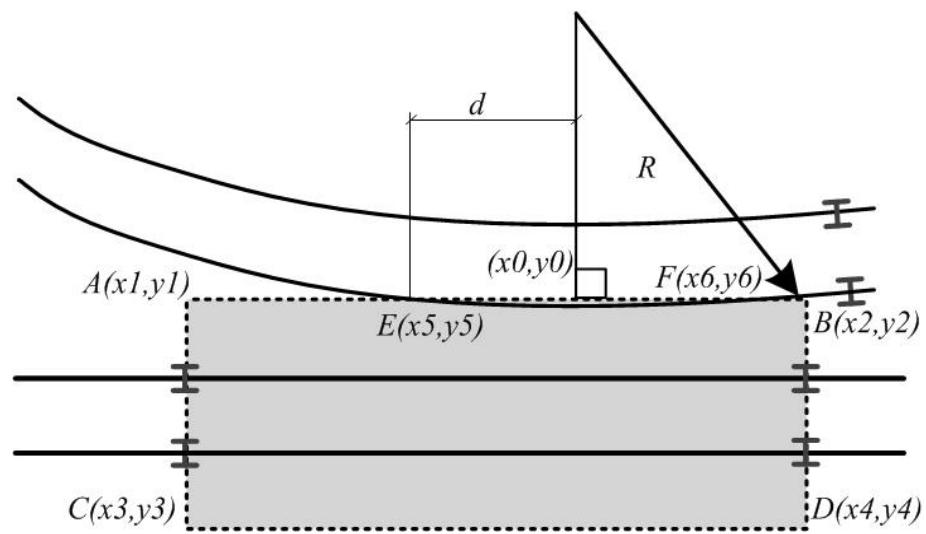

Рис. 7. Визначення перетину колійної ділянки радіусом R (EF) з ГЗВР 
Для виконання подальших розрахунків необхідно знайти найближчу до центру точку прямої ділянки колії з деякими координатами (x0, y0). По-перше, ця точка повинна знаходитися на такій відстані $L=\frac{|C|}{\sqrt{A^{2}+B^{2}}}$ від початку координат. По-друге, оскільки вектор $\overrightarrow{A B}$ перпендикулярний прямій, то координати цієї точки мають бути пропорційні координатам цього вектору. Враховуючи, що відстань від початку координат до шуканої точки відомі, то потрібно нормувати вектор $\overrightarrow{A B}$ до цієї довжини, а отже $[11,12]$ :

$$
\begin{aligned}
& x_{0}=-\frac{A \cdot C}{A^{2}+B^{2}} ; \\
& y_{0}=-\frac{B \cdot C}{A^{2}+B^{2}} .
\end{aligned}
$$

Якщо відстань від $\left(x_{0}, y_{0}\right)$ до початку координат більше радіусу, то точок перетину не існує. Якщо ця відстань дорівнює радіусу, то буде одна точка. В інших випадках точок перетину буде дві.

Шукані точки перетину колійних ділянок $\left(x_{5}\right.$, $\left.y_{5}\right)$ i $\left(x_{6}, y_{6}\right)$, окрім того, що повинні належати прямій $(A B)$, повинні лежати на одній і тій же відстані $d$ від точки $\left(x_{0}, y_{0}\right) d=\sqrt{R^{2}-\frac{C^{2}}{A^{2}+B^{2}}}[11,12]$.

Вектор $-\overrightarrow{A B}$ колінеарний прямій, а тому шукані точки $\left(x_{5}, y_{5}\right)$ i $\left(x_{6}, y_{6}\right)$ можна отримати, відповідно додавши та віднявши від точки $\left(x_{0}, y_{0}\right)$ вектор, що нормується до довжини $d[11,12]$ :

$$
\begin{aligned}
& x 5=x_{0}+B \cdot \sqrt{\frac{d^{2}}{A^{2}+B^{2}}} ; \\
& y 5=y_{0}-A \cdot \sqrt{\frac{d^{2}}{A^{2}+B^{2}}} ; \\
& x 6=x_{0}-B \cdot \sqrt{\frac{d^{2}}{A^{2}+B^{2}}} ; \\
& y 6=y_{0}+A \cdot \sqrt{\frac{d^{2}}{A^{2}+B^{2}}} .
\end{aligned}
$$

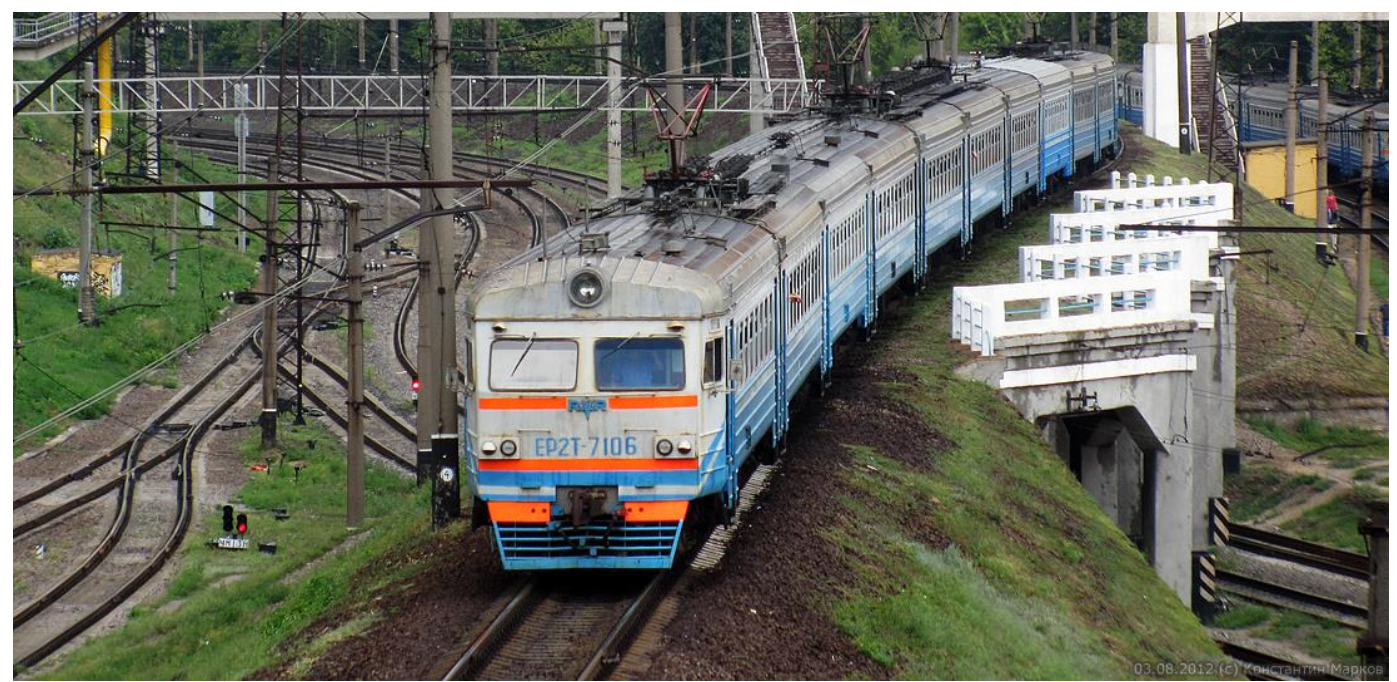

Рис. 9. Приклад колійного розвитку
Припустимо, що обидві колійні ділянки є кривими з радіусом $R$.

Визначення перетину зводиться до попереднього випадку, при якому отримано систему двох рівнянь $x^{2}+y^{2}=R_{1}^{2}$ та $\left(x-x_{2}\right)^{2}+\left(y-y_{2}\right)^{2}=R_{2}^{2}$. Виконавши перетворення, можна встановити, що завдання звелося про перетин двох кіл звелося до завдання про перетин першого кола і наступної прямої $[11,12]$ :

$$
A x+B y+C=0,
$$
випадку.

Подальше рішення аналогічно попередньому

Так як зона виконання робіт, як правило, обмежена елементом (стрілка, світлофор, стик) і має фронт декілька метрів, то для підвищення ефективності виконання робіт з'являється можливість розділити існуючі колійні секції на ділянки. Так, наприклад, виконання робіт на «ділянці 1» (рис. 8) виконується на убезпеченій відстані від маршруту, отже, не виникає необхідність в оповіщенні i припиненні робіт на час проїзду поїзда по «ділянці 3». Якщо роботи виконуються на «ділянці 2» необхідно виконувати оповіщення та припинення робіт на час проходу поїзду по «ділянці 3 ».

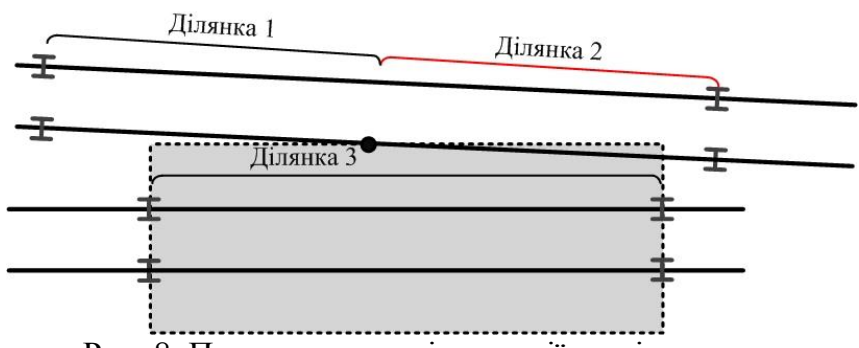

Рис. 8. Приклад розподілу секції на ділянки

У зв’язку з тим, що колійні ділянки можуть знаходитись на різній висоті $\mathrm{z}$ одна від одної, то виникає необхідність враховувати і координату $\mathrm{Z}$ (рис. 9). де $A=-2 x_{2}, B=-2 y_{2}, C=x_{2}{ }^{2}+y_{2}{ }^{2}+R_{1}{ }^{2}-R_{2}{ }^{2}$. 
Так при виконання робіт на елементі колійного розвитку, що розміщено вище небезпечної зони (згідно 3 [8] вище 10.75 м) небезпека для працівників відсутня. Тобто якщо координата $z$ елементу колійного розвитку, на якому виконуються роботи, більше на 10.75 м ніж координата $z$ сусіднього елементу, то відсутня небезпека для працівників станції при переміщенні рухомого складу по сусідній колії.

\section{5. Висновки}

Метод визначення убезпеченої зони виконання робіт на коліях, що засновано на геометричному представленні колійного розвитку, дозволяє обгрунтовано встановити небезпечні об'єкти та ділянки колійного розвитку при переміщенні рухомого складу.

Використання розробленого методу в системах автоматичного оповіщення дозволить підвищити ефективність проведення робіт на коліях, знизити як загальний травматизм, так і травматизм за смертельними наслідками.

\section{Література}

1. Правила технічної експлуатації залізниць України [Текст] / затв. наказом МТУ № 411 от 20.12.1996 г. зі змінами МТУ № 179 від 19.03.2002.

2. Системы предупреждения работающих на железнодорожных путях и информирования пассажиров о приближении железнодорожного подвижного состава. Общие требования. Национальный стандарт Российской Федерации ГОСТ Р 55804-2013 [Текст] / чинний від 2014.09.01. - М.: Стандартинформ, $2014-17$ с.

3. Буканов, М. А. Справочник дежурного по станции [Текст] / М. А. Буканов, Л. И. Педь, А. А. Шрамов. М.: Транспорт, 1987. - 239 с.

4. Бузанов, С. П. Охрана труда на железнодорожных станциях [Текст] / С. П. Бузанов, В. Ф. Харламов. - М.: Транспорт, 1986. - 284 с.

5. Охрана труда на железнодорожном транспорте [Текст] / под. ред. Ю. Г. Сибарова. - М.: Транспорт, 1981. $287 \mathrm{c}$.

6. Соболєв, Ю. В. Удосконалена автоматична система сповіщення працюючих на коліях - АСС УкрДАЗТ [Текст] / Ю.В. Соболєв, В. П. Мороз, О. В. Слізаренко та ін. // Збірник наукових праць Української державної академії залізничного транспорту. - 2005. - № 71. - С. 233-239.

7. Турчинов, Р. В. Застосування методу аналізу ієрархій при функціональному синтезі автоматизованих систем керування [Текст] / Р. В. Турчинов, С. О. Змій, В. П. Мороз, В. Ф. Кустов, В. І. Мойсеєнко // Східно-Европейський журнал передових технологій. - 2012. - Т. 2, № 3 (56). - С. 3336. - Режим доступу: http://journals.uran.ua/eejet/article/ view/3689/3456

8. ГОСТ 9238-83. Габариты приближения строений и подвижного состава железных дорог колеи 1520 (1524) мм. [Текст] / утв.и введ. 1984.07.01. - М.: Стандартинформ, 2000. -30 c.

9. Бекасов, В. И. Охрана труда. Технические средства защиты от наездов подвижного состава на людей. Методические указания для дипломного проектирования. Часть 1 [Текст] / В. И. Бекасов, В. И. Болотин, В. И. Жуков. - М.: ВЗИИТ, 1987. -54 с.

10. Сапожников, Вл. В. Эксплуатационные основы автоматики и телемеханики [Текст] / Вл. В. Сапожников и др.; под ред. Вл. В. Сапожников - М.: Маршрут, 2006. - 247с.

11. Бортаковский, А. С. Аналитическая геометрия в примерах и задачах [Текст] / А. С. Бортаковский, А. В. Пантелеев. - М.: Высш. шк., 2005. - 496 с.

12. Привалов, И. И. Аналитическая геометрия [Текст] / И. И. Привалов. - М.: Наука, 1966. - 272 с.

\section{References}

1. Pravyla tehnichnoi' ekspluatacii zaliznyc' Ukrainy: zatv. nakazom MTU № 411 ot 20.12.1996. Zi zminamy MTU № 179 vid 19.03.2002.

2. Sistemyi preduprezhdeniya rabotayuschih na zheleznodorozhnyih putyah i informirovaniya passazhirov o priblizhenii zheleznodorozhnogo podvizhnogo sostava (2013). Obschie trebovaniya. Natsionalnyiy standart Rossiyskoy Federatsii GOST R 55804-2013. Мщісщц: Standartinform, 17.

3. Bukanov, M. A., Ped, L. I., Shramov, A. A. (1987). Spravochnik dezhurnogo po stantsii. Transport, 239.

4. Buzanov, S. P., Harlamov, V. F. (1986). Ohrana truda na zheleznodorozhnyih stantsiyah. Transport, 284.

5. Sibarov, Yu. G. Ohrana truda na zheleznodorozhnom transporte (1981). Moscow: Transport, 287.

6. Soboliev, Yu. V., Moroz, V. P., Yelizarenko, O. V., Yelizarenko, A. O., Moroz, O. V. (2005). Udoskonalena avtomatychna systema spovishchennia pratsiuiuchykh na koliiakh. Zbirnyk naukovykh prats Ukrainskoi derzhavnoi akademii zaliznychnoho transport, 71, 233-239.

7. Turchynov, R. V., Zmij, S. O., Moroz, V. P., Kustov, V. F., Mojsejenko, V. I. (2012). Application of the method of analysis of hierarchies in functional synthesis of automated control systems. Eastern-European Journal of Enterprise Technologies. 2/3 (56), 33-36. Available at: http://journals.uran.ua/eejet/article/view/3689/3456

8. GOST 9238-83 (2000). Gabarity priblizhenija stroenij i podvizhnogo sostava zheleznyh dorog kolei 1520 (1524).

9. Bekasov, V. I., Bolotin, V. I., Zhukov, V. I. (1987). Ohrana truda. Tehnicheskie sredstva zashhity ot naezdov podvizhnogo sostava na ljudej. Metodicheskie ukazanija dlja diplomnogo proektirovanija. Part1. VZIIT, 54.

10. Sapozhnikov, Vl. V. (Ed.) (2006). Jekspluatacionnye osnovy avtomatiki i telemehaniki. Moscow: Marshrut, 247.

11. Bortakovskij, A. S., Panteleev, A. V. (2005). Analiticheskaja geometrija v primerah i zadachah. Moscow: Vyssha shkola, 496.

12. Privalov, I. I. (1966). Analiticheskaja geometrija. Moscow: Nauka, 272.

Рекомендовано до публікації д-р техн. наук Бойнік А. Б. Дата надходження рукопису 20.01.2015

Мороз Володимир Петрович, кандидат технічних наук, доцент, кафедра автоматики та комп’ютерного телекерування рухом поїздів, Українська державна академія залізничного транспорту, пл. Феєрбаха, 7, м. Харків, Україна, 61050

E-mail: onilbd@yandex.ru

Змій Сергій Олексійович, асистент, кафедра автоматики та комп'ютерного телекерування рухом поїздів, Українська державна академія залізничного транспорту, пл. Феєрбаха, 7, м. Харків, Україна, 61050

E-mail: onilsergey@yandex.ru 